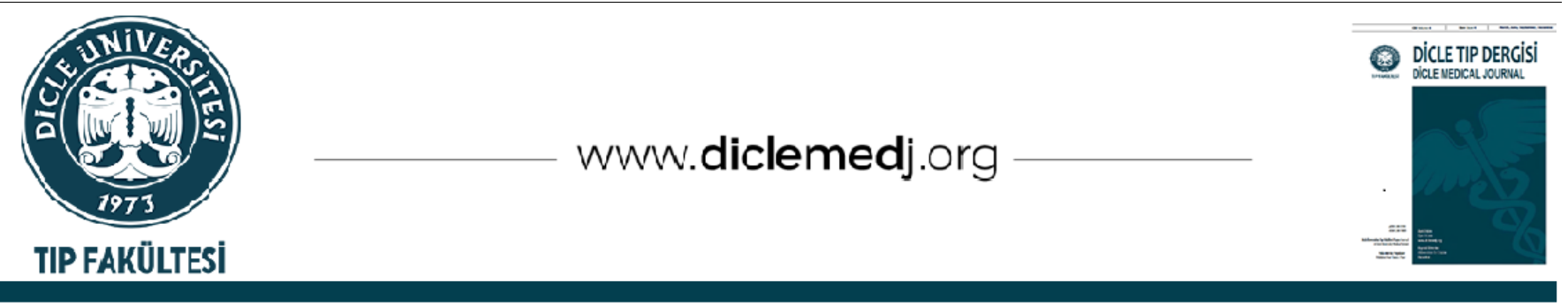

Derleme / Review

\title{
COVID-19 Yoğun Bakım Ünitelerinde Hava Yolu Yönetimi
}

\author{
Mahir Kuyumcu ${ }^{\text {D }} 1$ \\ 1 Dicle Üniversitesi Anesteziyoloji ve Reanimasyon AD Diyarbakır, Türkiye
}

Geliş: 22.09.2021; Kabul Tarihi: 29.09.2021

\section{$\ddot{\mathbf{O z}}$}

Çin'in Wuhan şehrinde ilk olarak tespit edilen Severe Acute Respiratory Syndrome Coronavirus 2 (SARS-CoV-2) tespit edildikten kısa süre sonra tüm dünyada ve ülkemizde de vakalar tespit edilmiştir. Vaka sayılarının artmasıyla hastalığın şiddetine göre önce yataklı servislerde daha sonra da yoğun bakım ünitelerinde yoğunluklar yaşanmıștır. Covıd-19 enfeksiyonu olan kişilerin ülkeden ülkeye hatta bölgesel olarak farklılık göstermekle birlikte \%20-26'lık bir kısmı hastanelere solunum sıkıntısı şikayetleri ile başvurmakta bu hastalarında \%5-10'luk kısmının yoğun bakım ihtiyacı olduğu bildirilmektedir. Covid-19 pandemisi ARDS ve multiorgan yetmezliklerine neden olarak hastalarda mekanik ventilatör ihtiyacı ve 3. basamak yoğun bakım takibi gerektirmektedir. Bu nedenle hastalığın bilinen spesifik tedavisi olmamasına rağmen yoğun bakım ünitelerinde sağlanan destek tedavisi ile hastalığın seyrindeki morbibite ve mortalite üzerine etkili olunmaktadır. Bu yazımızda akut solunum sıkıntısı olan ve solunum desteğine ihtiyaç duyan yeni tip koronavirüs enfeksiyonu hastalarına verilen solunum desteği ve hava yolu yönetimi anlatmayı amaçlıyoruz.

Anahtar kelimeler: Covid-19, yoğun bakım, Hava yolu

\section{Airway Management In COVID-19 Intensive Care Units}

\begin{abstract}
Severe Acute Respiratory Syndrome Coronavirus 2 (SARS-CoV-2) was detected for the first time in Wuhan, China, and cases were detected all over the world and in our country shortly after. With the increase in the number of cases, densities were experienced first in the inpatient services and then in the intensive care units, depending on the severity of the disease. Although it varies from country to country and even regionally, 20-26\% of people with COVID-19 infection apply to hospitals with respiratory distress complaints, and $5-10 \%$ of these patients are reported to need intensive care. The Covid-19 pandemic causes ARDS and multiorgan failure, requiring mechanical ventilators and 3rd step intensive care follow-up in patients. Therefore, although there is no known specific treatment for the disease, the supportive treatment provided in intensive care units is effective on the morbidity and mortality in the course of the disease. In this article, we aim to explain respiratory support and airway management given to patients with acute respiratory distress and new type of coronavirus infection who need respiratory support.
\end{abstract}

Keywords: Covid-19, Intensive care, Airway.

DOI: 10.5798/dicletip.1005351

Yazışma Adresi / Correspondence: Mahir Kuyumcu, Dicle Üniversitesi Anesteziyoloji ve Reanimasyon AD Diyarbakır, Türkiye e-mail: drmahirkuyumcu@gmail.com 


\section{GíRiş}

Aralık 2019'da Çin'in Wuhan şehrinde başlayan sonrasında bir halk sağlığı tehdidi olarak ortaya çıkan ve Şiddetli Akut Solunum Sendromu'na (SARS-CoV-2) neden olan yeni tip koronavirüs (COVID-19) Mart 2020'de Dünya Sağllk Örgütü tarafından pandemi etmeni olarak ilan edilmiştir ${ }^{1}$. Çin'de görülen ilk vaka sonrası yaklaşık 2 ay sonra ülkemizde de 10 Mart 2020 de ilk vaka tespit edilmiştir ${ }^{2}$. COVID-19 ile enfekte kişilerde \%14'ü ağır seyretmekte olup hastaların \%5'i temelde solunum sıkıntısı nedeniyle yoğun bakım ihtiyacı duymaktadır 3 . Yeni tip korona virüs enfeksiyonu olan kişilerin ülkeler arası hatta bölgesel farklıllklar göstermektedir4. Biz bu yazıda COVID-19 enfeksiyonu sonrası solunum sıkıntısı olan ve solunum desteğine ihtiyaç duyan hastalarda hava yolu yönetimini ve solunum destek ekipmanlarının kullanımı hakkında bilgi vermek amaçlanmıştır.

\section{COVID 19 TANISI VE YOĞUN BAKIMA KABULU}

COVID-19 enfeksiyonunun neden olduğu hastalı tablosu spesifik olmayan klinik bulgular ile diğer viral pnömonilerle ayrımını yapmak kolay değildir. Bunu yaparken ateş, seyahat öyküsü, pozitif tanı alan hastalarla temas öyküsü temel alınarak kohortlamaya gidilmelidir. PCR testlerinin sensitivitesi yanlış negatifliğe sebep olabilir. $\mathrm{Bu}$ nedenle tanıyı klinik ve tomografi görüntüleri ve öykü beraberinde değerlendirmek, yoğun bakıma ilk yatışta ve 24 saat sonra tekrarlanan örneklemeler yapmak gerekmektedir. COVID19 tanısı; solunum yolu örneklerinde viral RNA'yl saptamak için revers transkriptaz polimeraz zincir reaksiyonu (RT-PCR) kullanılmasına dayanmaktadır ${ }^{5}$. Hastaların Covid-19 yoğun bakım ünitelerine kabulü öncesi PCR testi pozitif olan veya COVID-19 şüpheli olguların ancak \%30-60'ında PCR testinin pozitif bulunabildiğinden yanlış negatif olasılığ aynı zamanda Covid-19 şüphesiyle birlikte Covid olmayan hastalarında Covid-19 yoğun bakım ünitesine alınmasını engellemek amaciyla bilgisayarlı toraks tomografisi ile radyolojik olarak bir radyolog tarafindan Covid19 pnömonisi ile uyumu onaylandıktan sonra hastalar yoğun bakıma kabul edilmesi imkanlar dahilinde daha uygun olacaktır.

COVID-19'da ağır hastalık tablosunda görülen solunum yetmezliği sıklıkla hipoksemik solunum yetmezliği tablosunda olup bu hastalara sıklıkla eşlik eden; ileri yaş, komorbid hastalık varlı̆̆ı (kardiyovasküler hastalık, diyabet, kronik respiratuar hastalık, hipertansiyon, kanser), erkek cinsiyet, obezite ağır hastalık gelişimi için risk faktörleridirø.

Günümüzde COVID-19'un hala etkin ve spesifik bir tedavisi bulunmuş değildir. Bu hastalarda hızla ARDS, sepsis ve multiorgan yetersizlikleri gelişebilmektedir. Hastaların yoğun bakım takip süreçlerinde hasta izolasyonu, solunum desteği (noninvaziv/invaziv), sıvı ve beslenme desteği ile sekonder bakteriyel enfeksiyonlara karşı antibiyoterapi önerilmektedir?

Yoğun bakım yataklarının bu dönemde daha verimli kullanılması ve ihtiyacı olan hastanın yoğun bakım ünitelerine ulaşması ve yoğun bakım yataklarının efektif kullanılması amacıyla sağlık bakanlığının hazırladığı rehber doğrultusunda yoğun bakıma kabul edilecek hasta kriterleri belirlenmiştir.

Sağlık Bakanlığı COViD-19 tedavi protokolü'ne göre hastanın takibinde aşağıdaki bulguların saptanması halinde hasta yoğun bakıma alınması önerilir8.

- Dispne ve solunum distresi olan

- Solunum sayısı $\geq 30 / \mathrm{dk}$

- $\mathrm{PaO} 2 / \mathrm{FiO} 2<300$ olan 
- Oksijen ihtiyacı izlemde artış gösteren

- 5 L/dk oksijen tedavisine rağmen SpO2 < \% 90 veya $\mathrm{PaO} 2<70 \mathrm{mmHg}$ olan

- Hipotansiyon (sistolik kan basıncl < 90 mmHg ve olağan SKB dan $40 \mathrm{mmHg}$ dan fazla düşüş ve ortalama arter basıncı $<65 \mathrm{mmHg}$, taşikardi > $100 / \mathrm{dk}$

- Akut böbrek hasarı, akut karaciğer fonksiyon testlerinde bozukluk, konfüzyon, akut kanama diyatezi gibi akut organ disfonksiyonu gelişimi ve immünsüpresyonu olan hastalar

- Troponin yüksekliği ve aritmi

- Laktat > 2 mmol

Kapiller geri dönüş bozukluğu ve cutis marmaratus gibi cilt bozukluklarının varlığı

$\mathrm{Bu}$ kriterlere sahip hastaların değerlendirilmesi için yoğun bakım sorumlu hekimlerinden konsultasyon istenmesi önerilir. Yoğun bakım ünitesine yatış kararı yoğun bakım sorumlusu ile birlikte verilir.

Yoğun bakıma yatış endikasyonu olan hastalar hızla klinik kötüleşme gösterebileceğinden vital bulguları (kalp hızı, ritmi, solunum sayısı, kan basıncı, vücut ısısı, oksijen satürasyonu) düzenli olarak takip edilir. İlerleyici solunum yetmezliği ve sepsis açısından dikkatli olunmalıdır. Hastaların tam kan sayımı (özellikle lenfosit sayısı), rutin biyokimyasal parametrelere ilave C-reaktif protein, troponin, D-dimer, ferritin, prokalsitonin seviyeleri, böbrek ve karaciğer fonksiyonları, kardiyak enzimleri, koagülasyon parametreleri (fibrinojen, PT/aPTT), arter veya venöz kan gazı, laktat, elektrolit değerleri, akciğer grafisi yatış sırasında istenir ve düzenli aralıklarla takip edilir. Antibiyotik tedavisi öncesinde kültürleri alınır. Hastalar yoğun bakım yatışı sırasında komorbid hastalıkları açısından da değerlendirilmeli ve öncesinde kullanılan tedavi rejimleri de düzenlenmelidir. COVID- 19'da hipertansiyon ve diyabet en sık görülen komorbid hastalıklardır ${ }^{8-9}$.
Ayrıca hastaların sitokin paneli ve anjiotensin II seviyesi değerlendirilmeli, günlük EKG çekimleri yapılmalı, QTc uzamasına neden olabilecek ilaç etkileşimlerinden kaçınılmalı, klinik kötüleşmede akciğer X-ray, USG takipleri yapılmalıdır. Troponin seviyesi yükselecek olursa sol ventrikül fonksiyonları değerlendirilmelidir.

\section{HAVA YOLUNUN AÇIK TUTULMASI}

Hava yolunun açık tutulması hava yolu yönetiminde en önemli ayağı oluşturmaktadır. Bunun içinde hastanın çok yakın takip edilmesi en önemli kısmı oluşturmaktadır. Bu yakın takiple birlikte gerektiğinde hastanın hava yolunun açılması ve açık tutulması ile ilgili her işlem entübasyon, balon-valf-maske uygulaması, trakeostomi, non invaziv mekanik ventilasyon (BIPAP-CPAP maske uygulaması), yüksek akımlı nazal oksijen uygulaması (HFNO), bronkoskopi, kardiyopulmoner resusitasyon (KPR) işlemlerinin hepsi farklı düzeylerde aerosol oluşturmakta ve virusun yayılma riskini artırmaktadır ${ }^{10}$. Bu durumda da sağlık çalışanlarının bulaş nedeniyle güvenlik sorununu getirmektedir. Bu noktada önemli olan sağlık çalışanların kişisel koruyucu ekipmanılarının (KKE) eksiksiz temini ve ulaşılabilinir olması gerekmektedir. KKE lar [su geçirmez önlük, maske (N95/FFP2), gözlük/yüz koruyucu siperlik ve eldiven] tam olarak uygulamalıdır. KKE'lar giyilirken ve çıkartılırken kurallara uyulmalı çalışanlar bu konuda bir birini uyarmalı ve yardımcı olmalıdır ${ }^{11}$. Tüm bu önlemlerin sonunda el yıkama ihmal edilmemelidir.

Periferik oksijen satürasyonu (Sp02)<\% 92'nin altında ise oksijen desteği verilmelidir ${ }^{11-12}$. Covid 19 ile enfekte ve hastalık belirtisi gösteren hastaların büyük çoğunluğu oksijen desteğine ihtiyaç duymazlar, oksijen desteğine ihtiyacı olan hastaların da büyük çoğunluğu nazal kanül ile verilen düşük akımda oksijene yanıtları iyi olmaktadır. Hastaların \%5 lik küçük bir grubu (özellikle eşlik eden kronik hastalığı 
bulunan, immun süprese ve malignitesi olan hastalar), ilerleyici solunum yetmezliği nedeni ile daha fazla solunum desteğine ihtiyaç duyarlar ${ }^{13-14}$.

\section{GELENEKSEL YÖNTEMLERRLE OKSİJEN TEDAVISI}

Oksijen tedavisi geleneksel olarak bilinen düșük akım (<15L/dk.) veya yüksek akım yöntemleri ile uygulanabilir. İlk olarak nazal kanül ile oksijen desteği başlanmalı bu yöntem ile en fazla $6 \mathrm{~L} / \mathrm{dk}$. oksijen verilebilir, buda ulaşılabilinecek maksimum $\mathrm{FiO}$ \%45 civarındadır. $6 \mathrm{~L} / \mathrm{dk}$. üzerinde oksijen ihtiyacı olan hastalarda basit yüz maskesine geçilerek 58 L/dk. Oksijenle hedef FiO2 \%60'a kadar çıkılabilir, daha yüksek FiO2 değerlerine ulaşmak için rezervuarlı (geri solumasız) maske ile 10-15 L/dk. oksijen akım hızı ile FiO2 \%85'lere ulaşılabilinir. 6 saati aşan süre ile FiO2'nin de \%60'ın üzerinde uygulanmasının oksijen toksisitesine yol açabileceğide unutulmamalıdır.

Akut hipoksemik solunum yetersizliği olan erişkinlerin tedavisinde, Sp02 \%92-96 olacak şekilde uygun olan nazal kanul veya maske ile oksijen desteği sağlanarak hedefin tutulması önerilmektedir. Hastalarda damlacık yolu ile enfeksiyon bulaşma riskinin azaltılması adına nazal oksijen kanülü üzerine cerrahi maske uygulanabilir. Eğer 6 L/dk. Üzerinde yüksek akım ihtiyacı varsa yeniden solumaya izin vermeyen rezervuarlı oksijen maskelerinin kullanılması ile bulaşın azaltılması düşünülmelidir. Covid-19 ve geleneksel oksijen tedavisine rağmen akut hipoksemik solunum yetersizliği olan (SpO2 \% 90'nın altında) yetişkinlerde klasik oksijen tedavisi yerine yüksek akımlı nazal oksijen (HFNO) tedavisi kullanılması önerilmektedir ${ }^{15}$.

Dünya Sağlık Örgütü Covid-19 hastalarında Sp02 hedefinin \%90-96 arasında tutulması gerektiğini belirtmektedir ${ }^{1}$.

\section{YÜKSEK AKIMLI NAZAL OKSIJJEN (HFNO)} TEDAVISİ

HFNO cihaza özgü bir nazal kanul yolu ile dakikada 60 litreye kadar yüksek miktarlarda hava ve oksijen karışımı verebilen, FiO2'i \%21\%100 arasında oksijen verecek şekilde tasarlanmış cihazlardır. HFNO temel olarak; hastanın konforunun sağlanması amacıyla, verilen oksijenin nemlendirilip ve isitılarak hastaya ulaşmasını sağlamak. Ayrıca sekresyonların mobilize edilmesi, geleneksel yöntemlerle oluşan nazal ve ağız kuruluğunun engellenmesi, üst hava yolunda ölü boşluğun azaltılması ve sürekli olarak verilen yüksek akımla doğru orantılı olarak devamlı havayolu basınci oluşturarak (CPAP) etkisiyle açılklanabilirir-17.

HFNO cihazları farklı markalara göre değişmekle birlikte 5-60 L/dk akım verebilmektedirler. Akımdaki artış uygulanan CPAP düzeyini de doğru orantılı olarak artırmaktadır. Böylelikle hastalarda intrensek PEEP'in oluşumu ile solunum iş yükünü azaltmaktadır. HFNO cihazları ile uygulanan CPAP düzeyi birçok faktörden etkilenmekle birlikte ortalama her $10 \mathrm{~L} / \mathrm{dk}$ lık akım artışında 0,3-0,7 cmH20 basınç artışı sağlamaktadır ${ }^{16,18}$.

Cihaz hastalara ilk bağlandığında başlangıçta 20 $\mathrm{L} / \mathrm{dk}$ akım ile başlanır ve gerektiğinde akımda 5-10 Lt/dk'lık artışlar yapılır. HFNO cihazları ile FiO2 \%21-100 arasında ayarlanabilir. Oksijen toksisitesinden kaçınmak için klinik izin verdiği sürece FiO2\%60'ın altında tutulmaya çalışılmalıdır. HFNO akımı $20 \mathrm{~L} / \mathrm{dk}$ 'nın altına ve FiO2 \%50'nin altına düşmesi sonrası hastanın klasik oksijen destek yöntemleriyle oksijenlenmesi değerlendirilmelidir. HFNO uygulanırken damlacık yayılımı konusunda tersini iddia eden çalışmalar mevcut olsa da haklı endişeler mevcuttur. Hastalar mümkünse tek kişilik ve negatif basınçlı ya da en azından penceresi açlabilen odalarda izlenmelidir. HFNO uygulaması sırasinda buruna tam oturan bir ara yüz ve düşük akım uygulanması ile virüs 
saçlımında diğer oksijen desteği uygulamalarına göre artış olmayacağı ya da çok az olacağı düşünülmektedir. Ancak akım hızı arttıkça virüs saçılmasının arttığını gösteren çalışmalar da vardır ${ }^{19}$.

Solunum desteğine ihtiyaç duyulan ve geleneksel düşük akımlı oksijen tedavisi yöntemleri ile başarı sağlanamayan hastalarda HFNO ve Non-Invasiv Mekanik Ventilasyon (NIMV) uygulaması düşünülmelidir. HFNO ve NIMV uygulaması hastaların entübasyon ihtiyacında azalmasına katkı sağlayabilir.

Sepsis Sağkalım Kampanyası'nın (Surviving Sepsis Campaign), kritik hastalardaki koronavirüs hastalarına yönelik yayınlanan rehberinde; invaziv mekanik ihtiyacında azalma, 90 günlük mortalitede azalma, yoğun bakımda kalış süresinin kısalması gibi nedenlerle HFNO'nun NIMV'e tercih edilmesini tavsiye edilmektedir ${ }^{11-20}$.

Ayrıca uzun süre yüksek oranda oksijen kullanımı hastalarda oksijen toksisitesine neden olabilmektedir. HFNO veya NIMV kullanılarak ihtiyaç duyulan oksijen miktarı düşürülmesi ile oksijen tedavisinin istenmeyen etkilerinden uzaklaşılması sağlanabilir.

\section{NON-INVAZIV POZITIF BASINÇLI MEKANIK VENTILASYON (NIPPV)}

Geleneksel yöntemler ve HFNO ile oksijen tedavisi uygulanması sirasında yakın monitörizasyon ile hastaların izlenmesi son derece önem taşır. Bu hastalar maalesef klinik olarak hızla bozulabilen ve acil entübasyon ihtiyacı olabilen hastalardır. HFNO mevcut değilse ve acil endotrakeal entübasyon endikasyonu da yok ise, non invaziv pozitif basınçlı ventilasyon maske veya Helmet ile (NIPPV) yakın izlem ve entubasyon açısından aralıklı klinik değerlendirme ile uygulanabilir ${ }^{11}$. Helmet veya miğfer NIPPV kullanımı çalışan güvenliğinin sağlanması amacı ile kullanılması önerilse de kullanımı açısından dikkatli olunması gereken durumlara dikkat ediilmeli.
Helmet maskede çiftli solunum devresi kullanılmalı, hem inspirasyon hem ekspirasyon solunum hattına virüs engelleyici özelliği olan filtrelerin takılması önerilmektedir. Yoğun sekresyonu olan, hava yolu açıklığını koruyamayan, hemodinamik açıdan stabil olmayan veya bilinç bulanıklığı olan hastalarda Helmet maskesi uygulanmamalıdır. Ayrıca Helmet tipi maskeler tercih edildiğinde verilen tidal volümün yaklaşık \%50-75'i maskenin içine kalır, kullanıcılar büyük orandaki ölü boşluğu göz önüne bulundurmalıdır. Helmet tipi maske kullanımında ölü boşluk ve CO2 geri soluması nedeni ile hiperkarbiye dikkat edilmelidir ${ }^{21,22}$. NIPPV veya HFNO alan erişkinlerde, solunum yakından izlenmelidir, kötüleşme meydana geldiğinde elektif şartlarda erken entübasyon önerilmektedir. Covid-19 şiddetli hipoksemik solunum yetmezliği olan uyanık, spontan solunum yapan hastalar için pron pozisyonun kullanımının oksijenizasyonu iyileștirebileceği, NIMV sırasında dahi kullanılabileceği de belirtilmiştir ${ }^{19}$.

Maske ile NIPPV uygulanan hastalar mümkünse negatif basınçlı izole odalarda değilse hepa filtreli ya da penceresi açllabilir odalarda işlem gerçekleştirilmelidir ${ }^{23}$.

Sekresyonların kontrolünün olmadığl, aspirasyon riski yüksek olan, hemodinamik bozukluğu olan, mental durumunda gerileme olan veya multiorgan yetmezliği tablosunda olan hastalarda NIV'den kaçınılmalıdır.

\section{İNVAZIV MEKANİK VENTİLASYON}

Mevcut non-invaziv yöntemlerle \% 60'ın üzerinde FiO2'ye rağmen $\mathrm{SpO2< \% 90} \mathrm{veya}$ uygun destek tedaviye rağmen solunum iş yükünde azalma yoksa, hastanın kliniğinde hızlı kötüleşme mevcutsa, hiperkapni, Transpulmoner basıncın fazla, ciddi dispne ve takipnesi olan (solunum sayısı $>30$ ), mental durumda bozulma, hemodinamik bozukluk mevcutsa hastalar entübe edilmelidir. 
Entübasyon Covid-19 hastalarında damlacık bulaşı için en yüksek riskli işlemdir ${ }^{24-25}$.

Yüksek aerosol riskine karşı işlem sırasında KKE giymiş, en az sayıda kişiyle, entübasyon malzemelerinin önceden hazır olduğu ve entübasyon sırasında maksimum güvenliğin sağlandığı koşullarda, mümkünse negatif basınçlı izole odalarda değilse hepa filtreli ya da pencere açlabilir odalarda işlem gerçekleştirilmelidir ${ }^{23}$.

Entübasyon sırasında preoksijenizasyon rezervuarlı maske ile yapılmalı, mümkün olduğunca balon-valf-maske uygulamasından kaçınılmalı. Balon-valf-maske kullanılması gerekiyorsa, maske ile balon arasına virüs filtresi yerleştirilmelidir ve maskenin yüze tam oturduğundan emin olunmalıdır. Düşük tidal volümler ile hasta havalandırılmalıdır. Apneik oksijenasyon düşünülüyorsa 15L/dk. nazal oksijenasyon uygulanabilir. Tecrübeli kişiler tarafından yapılmalı. Hızlı ardışık entübasyon uygulanmalı, öğürme ve öksürüğü önlemek için nöromusküler blokaj ile tam kas gevşemesi sağlanmalıdır. Videolaringoskop ile işlem gerçekleştirilmelidir ${ }^{26,28}$. Endotrakeal tüpün kafı şişirilmeden hasta mekanik ventilatöre bağlanmamalı ve havalandırılmamalıdır. Trakeal tüpün yeri kapnografi ile doğrulanmalıdır. Solunum devresi ile endotrakeal tüp arasına filtre yerleştirilmelidir. Mekanik ventilatörlerde çift hatlı devrelerin kullanıldığı cihazlar tercih edilmeli, inspiryum ve ekspiryum hatlarına virüs tutucu filtreler yerleștirilmelidir. Kapalı devre aspirasyon sistemi, hasta ventilatöre bağlanmadan solunum devresine bağlanmalı ve zorunlu olmadıkça devre bütünlüğü bozulmamalıdır ${ }^{29}$.

Son bir haftada ortaya çlkan veya kötüleşen solunum sıkıntısı kalp yetmezliği veya volüm fazlalığı ile açıklanamıyorsa (transtorasik ekokardiyografi ile sol ventrikül disfonksiyonunun olmadığı gösterilmelidir); radyolojik olarak plevral efüzyon, kollaps ile açılklanamayan bilateral multilober buzlu cam dansiteleri eşlik ediyorsa ve $\mathrm{PaO} 2 / \mathrm{FiO} 2<300$ ise hasta ARDS olarak tanımlanır ${ }^{30}$.

\section{Berlin Tanı Kriterlerinde Oksijenizasyona göre ARDS Sınıflaması}

Hafif ARDS: $201<\mathrm{PaO} 2 / \mathrm{FiO} 2 \leq 300$ (PEEP $\geq 5$ cmH20)

Orta ARDS: $101<\mathrm{PaO} 2 / \mathrm{FiO} 2 \leq 200$ (PEEP $\geq 5$ cmH20)

Ağır ARDS: PaO2/FiO2 $\leq 100$ (PEEP $\geq 5$ cmH20)

Hastaların semptom başlangıcı ve radyolojik bulguları Berlin kriterlerine uymamaktadır. Gattinoni ve arkadaşları tarafınca hipoksemi 3 farklı mekanizma ile açıklanmıştır. Bunlar pulmoner perfüzyonda disregülasyon, akciğer parankiminde mikrotrombüsler ve kardiyojenik olmayan pulmoner ödem (ARDS benzeri) olarak belirtilmiştir ve hastalar $\mathrm{H}$ ve $\mathrm{L}$ olmak üzere 2 fenotipe ayrılmıştır. Fenotip L tipI (sesiz hipoksemi) olan hastalardaki mekanizma pulmoner perfüzyonda disregulasyon ve mikrotrombüslerle açıklanırken bu fenotipe sahip hastaların elastanslarının, ventilasyon-perfüzyon oranlarının düşük olduğu; hastaların rekruitment, pron pozisyona ve yüksek PEEP'e cevap vermedikleri gözlenmiştir. Bu hastalarda şant fraksiyonu yüksek olduğundan sağ kalp venöz doluşunu etkileyecek yüksek PEEP uygulanması vazoaktif ajan gereksinimini arttırabilir. $\mathrm{Bu}$ hasta grubunda uygulanacak oksijen destek tedavileri; HFNO, CPAP, NIPPV uygulamaları düşünülmelidir, PEEP düşük, soluk hacmi daha yüksek tutulabilir $(6-8 \mathrm{~mL} / \mathrm{kg})$ dakika solunum sayısı 15-20 şekilde mekanik ventilasyon değerleri ayarlanmalıdır. Fenotip H'deki hastalarda ise elastans yüksek ve kompliyans düşük saptanmıştır. Bu hastalarda rekruitment, prone pozisyon uygulanması ve yüksek PEEP'in ARDS'dekine benzer olumlu etkileri olduğu gözlenmiştir. Mekanik ventilasyon ayarlarının hastaya özgü olarak düzenlenmesi gereklidir. Sp02>\%90 olacak şekilde yüksek PEEP'i mümkün olan en düşük 
PEEP, en düşük FiO2 en düşük tepe basıncı hedeflenmelidir Hastalığın ilerleyen safhalarında $\mathrm{L}$ fenotipinden $\mathrm{H}$ fenotipine geçiş olabileceği belirtilmiștir $28-31$.

Koruyucu akciğer ventilasyonunu kolaylaştırmak için gerektiğinde nöromüsküler bloke edici ajanların (NMBA) aralıklı boluslar halinde kullanılması önerilmektedir. Ventilatöre uyumsuzluk, derin sedasyon gereksiniminin devam etmesi, pron ventilasyon veya inatçı yüksek plato basınçları olması durumunda, 48 saate kadar sürekli NMBA infüzyonu kullanılabilir. Optimal ventilasyona rağmen Covid-19 ve hipoksemisi olan yetişkinler için recruitment manevraları kullanılabilir. Mekanik ventilatör modlarında tercih ise en çok hakim olunan modların kullanılması hastalar için daha faydalı olacaktır.

Covid-19 ve mekanik ventilasyon uygulanan erişkinlerde optimal ventilasyon, kurtarma tedavileri ve pron pozisyona rağmen refrakter hipoksemi devam ediyorsa venö-venöz (VV) ekstra korporeal membran oksi- jenizasyonu (ECMO) kullanılması veya hastanın bir ECMO merkezine yönlendirilmesi önerilmektedir ${ }^{11}$.

\section{PRONE POZISYYNU}

Covid-19 pnömonisi olan hastalarda pron pozisyonun etkinliği klinik çalışmalarla ve sahada çalışan hekimlerin gözlemleri ile kanıtlanmıștır. Ciddi ARDS bulguları gösteren ve PaO2/FIO2 oranın $150 \mathrm{mmHg}$ nın altında olan hastalara pron pozisyon verilmelidir ${ }^{11}$. Pron pozisyon süresi en az 12-16 saat olmalıdır. Hastaların uyumlu olması halinde entübe olmayan spontan solunumdaki oksijen desteği alan hastalarla HFNO ve NIPPV uygulanan solunumyetersizliği olan pnömonili olgularında da pron pozisyon denenebilir. Pron pozisyon etki mekanizması; hastaların ventilasyon/perfüzyon oranlarını iyileştirmesi ve fizyolojik şantı azaltması, sekresyonların mobilize olması, dependan akciğer bölgelerinde havalanmayı artırması ve daha homojen bir havalanma sağlaması, fonksiyonel reziduel kapasitenin artması, ventilatör ilişkili akciğer hasarının azalması olarak sayılabilir.

Çıkar Çatışması Beyanı: Yazarlar çıkar çatışması olmadığını bildirmişlerdir.

Finansal Destek: Bu çalışma her hangi bir fon tarafından desteklenmemiştir.

Declaration of ConflictingInterests: The authors declare that they have no conflict of interest.

Financial Disclosure: No financial support was received.

\section{KAYNAKLAR}

1. WHO Director-General's opening remarks at the media briefing on COVID-19 - 11 March 2020. (Available: https:// www.who.int/dg/speeches/detail/who-directorgeneral- s-opening-remarks-at-the-media-briefingon-covid- 19\%2D\%2D-11-march-2020.) [cited 12 Mar 2020].

2. COVID-19 outbreak control, example of ministry of health of Turkey. Demirbilek Y, Pehlivantürk G, Özgüler ZÖ, Meşe EA. Turk J Med Sci, 50, (2020), 489-94.

3. Team NCPERE. Vital surveillances: The epidemiological characteristics of an outbreak of 2019 novel coronavirus diseases (COVID-19) China. China CDC Weekly. 2020; 2: 113-22.

4. Young BE, Ong SWX, Kalimuddin S, et al. Epidemiologic Features and Clinical Course of Patients Infected With SARS-CoV-2 in Singapore. JAMA. 2020; 323: 1488-94.

5. Chunqin l, Huaxiang X, Qinglin S, Xianghai Z, Bing $\mathrm{F}$, et al. Diagnosis of the Coronavirus disease (COVID-19): rRT-PCR or CT? European Journal of Radiology. 2020; 126: 108961.

6. Wu Z, McGoogan JM. Characteristics of and important lessons from the coronavirus disease 2019 (COVID-19) outbreak in China: Summary of a report of 72314 cases from the Chinese center for disease control and prevention. Jama. $2020 \mathrm{Feb} 24$. (Online ahead of print). 
7. WHO: coronavirus disease 2019 (COVID19) situation report - 23. Geneva, Switzerland: World Health Organization; 2020. https://www.who.int/docs/defaultsource/coronav iruse/situation-reports/20200212- sitrep20200223 ncov.pdf?sfvrsn= $20200241 \mathrm{e} 20200219 \mathrm{fb} 20200278 \quad 20200212$ [accessed 20200213 February 20202020].

8. T.C. Sağlık Bakanlığı Covid 19 Rehberi 27 Mayıs 2021. https://covid19bilgi.saglik.gov.tr/tr/covid19- rehberi.htm

9. Guan W, Liang W, Zhao Y, et al. China Medical Treatment Expert Group for COVID-19. Comorbidity and its impact on 1590 patients with COVID-19 in China: A nationwide analysis. Eur Respir J. 2020; 55 : 2000547.

10. Tran K, Cimon K, Severn M, Pessoa-Silva CL, Conly J. Aerosol-Generating procedures and risk of transmission of acute respiratory infections: A systematic review. PLoS One. 2012; 7: e35797.

11. Alhazzani W, Moller MH, Arabi YM, et al. Surviving Sepsis Campaign: Guidelines on the management of critically Ill adults with coronavirus disease 2019 (COVID-19). Intensive Care Med. 2020; 46: 854-87.

12. Clinical management of COVID-19. Interim guidance 27 May 2010. World Health Organization. WH072019-nCoV/ clinical/2020.5. (https://apps.who.int/iris/handle/10665/332196)

13. Huang C, Wang Y, Li X, et al. Clinical features of patients infected with 2019 novel coronavirus in Wuhan, China. Lancet. 2020; 395: 497.

14. Yang $\mathrm{X}, \mathrm{Yu} \mathrm{Y,Xu} \mathrm{J}$, et al. Clinical course and outcomes of critically ill patients with SARSCoV-2 pneumonia in Wuhan, China: a singlecentered, retrospective, observational study. Lancet. 2020; 8: 475-81.

15. Lamontagne F, Rochwerg B, Lytvyn L, et al. Corticosteroid therapy for sepsis: A clinical practice guideline. BMJ. 2018; 362: k3284.

16. Sztrymf B, Messika J, Mayot T, et al. Impact of high-flow nasal cannula oxygen therapy on intensive care unit patients with acute respiratory failure: a prospective observational study. J Crit Care. 2012; 27: 324.e9.

17. Parke RL, McGuinness SP. Pressures delivered by nasal high flow oxygen during all phases of the respiratory cycle. Respir Care. 2013; 58: 1621.

18. SLenglet H, Sztrymf B, Leroy C, et al. Humidified high flow nasal oxygen during respiratory failure in the emergency department: feasibility and efficacy. Respir Care. 2012; 57: 1873.

19. Coppo A, Bellani G, Winterton D, et al. Feasibility and physiological effects of prone positioning in non-intubated patients with acute respiratory failure due to COVID-19 (PRON-COVID): A prospective cohort study. Lancet Respir Med. 2020; 8: 765-74.

20. Ni YN, Luo J, Yu H, et al. The effect of high flow nasal cannula in reducing the mortality and the rate of endotracheal intubation when used before mechanical ventilation compared with conventional oxygen therapy and noninvasive positive pressure ventilation. A systematic review and meta-analysis. Am J Emerg Med. 36: 226-33.

21. Vargas F, Thille A, Lyazidi A, et al. Helmet with speciKc settings versus facemask for noninvasive ventilation. Critical Care Medicine. 2009; 37: 19218.

22. Mojoli F, Lotti GA, Gerletti M, et al. Carbon dioxide rebreathing during non-invasive ventilation delivered by helmet: a bench study. Intensive Care Medicine. 2008; 34: 1454-60.

23. Talan L, Altıntaș ND. Yoğun Bakımda Hasta Yönetimi/ COVID-19. Ankara Üniversitesi Tıp Fakültesi. Ankara Üniversitesi Basımevi 2020. (Ekitap)

24. Cheung JC, Ho LT, Cheng JV, Cham EYK, Lam KN. Staff safety during emergency airway management for COVID19 in Hong Kong. Lancet Respir Med. 2020;8

25. El-Boghdadly K, Wong DJN, Owen R, et al. Risks to healthcare workers following tracheal intubation of patients with COVID-19: a prospective international multicentre cohort study. Anaesthesia. 2020.

26. Karabıyık L. COVID-19 hastaların yoğun bakım süreci. Gazi Medical Journal 2020; 31: 331-6. 
27. Agarwal A, Basmaji J, Muttalib F, et al. High-Flow nasal cannula for acute hypoxemic respiratory failure in patientswith COVID-19: Systematic reviews of effectiveness and its risks of aerosolization, dispersion, and infection transmission. Can J Anaesth. 2020; 67: 1217-48.

28. Gattinoni L, Chiumello D, Caironi P, et al. COVID19 pneumonia: Different respiratory treatments for different phenotypes? Intensive Care Med. 2020; 46: 1099-102.
29. Tobaiqy M, Qashqary M, Al-Dahery S, et al. Therapeutic management of patients with COVID19: A systematic review. Infection Prevention in Practice. 2020; 2: 100061.

30. Ranieri VM, Rubenfeld GD, Thompson BT, et al. Acute respiratory distress syndrome: the Berlin Definition. Jama. 2012; 307: 2526-33.

31. Gattinoni L, Coppola S, Cressoni M, et al. COVID19 Does Not Lead to a "Typical" Acute Respiratory Distress Syndrome. Am J Respir Crit Care Med. 2020; 201: 1299-300. 